\title{
PELATIHAN MEDIA PEMBELAJARAN DARING GUNA MENUNJANG PERAN ORANG TUA DALAM PANDEMI COVID-19
}

\author{
Irma Darmayanti 1), Pungkas Subarkah¹, Luki Rafi Anuggilarso'), Jali Suhaman1) \\ 1)Program Studi Informatika, Fakultas IImu Komputer, Universitas Amikom Purwokerto, Purwokerto, JawaTengah, \\ Indonesia \\ Corresponding author : Irma Darmayanti \\ E-mail : irmada@amikompurwokerto.ac.id
}

Diterima 08 Oktober 2021, Direvisi 18 Oktober 2021, Disetujui 18 Oktober 2021

\begin{abstract}
ABSTRAK
Pandemi covid-19 yang tidak kunjung berakhir dan terus di perpanjangnya kebijakan PPKM membuat kegiatan belajar mengajar masih belum bisa dilaksanakan secara tatap muka meski telah memasuki tahun ajaran baru. Untuk itu adanya kegiatan Amikom Mitra Masyarakat, tim kami melakukan pelatihan penggunaan media pembelajaran daring kepada masyarakat luas khususnya orangtua dengan tujuan dapat meningkatkan kesadaran orangtua akan pentingnya peran orangtua dalam mengoptimalkan kualitas proses belajar daring. Metode yang dilakukan adalah dengan Participatory Action Research (PAR), dimana tim melakukan observasi guna mengidentifikasi permasalahan dan peluang mitra dampingan pada awal tahun 2021 yang kemudian dilanjutkan dengan pelaksanaan kegiatan yang dilakukan secara daring diawal tahun ajaran baru dan terakhir melakukan evaluasi hasil kegiatan. Kegiatan pelatihan diikuti 59 peserta selama berlangsungya kegiatan sangat antusias sampai selesai pelatihan ini. Sebanyak $74,58 \%$ peserta dapat memahami penggunaan media pembelajaran daring dari hasil pelatihan tersebut.
\end{abstract}

Kata kunci: media pembelajaran; daring; pandemi; peran orang tua.

\begin{abstract}
The ongoing COVID-19 pandemic and the continued extension of the PPKM policy have made teaching and learning activities unable to be carried out face-to-face even though it has entered the new school year. For this reason, with the Amikom Mitra Masyarakat activity, our team conducts training on the use of online learning media to the wider community, especially parents, with the aim of increasing parental awareness of the importance of parents' role in optimizing the quality of the online learning process. The method used is Participatory Action Research (PAR), where the team conducts observations to identify problems and opportunities of assisted partners in early 2021, which is then followed by the implementation of activities carried out online at the beginning of the new school year and finally evaluates the results of activities. The training activity was attended by 59 participants during the activity very enthusiastically until the completion of this training. A total of $74.58 \%$ of participants were able to understand the use of online learning media from the results of the training.
\end{abstract}

Keywords: learning media;online; pandemic; the role of parents.

\section{PENDAHULUAN}

Pandemi Covid-19 berlangsung di Indonesia sejak pertengahan Maret 2020 dan masih saja belum bisa diakhiri hingga pertengahan tahun ini. Setiap hari lebih dari 4000 jiwa terkonfirmasi positif Covid-19, hal ini menyebabkan beberapa daerah terutama daerah diwilayah zona merah memberlakukan PPKM (Pemberlakuan Pembatasan Kegiatan Masyarakat). Salah satu sektor yang sangat terdampak oleh pandemi Covid-19 adalah sektor pendidikan (Ananda, Rizki., Fadhilaturrahmi., 2021) .

Pendidikan di Indonesia mengalami perubahan pola pembelajaran, hal ini berpengaruh pada perubahan pola belajar peserta didik. Banyak peserta didik yang mengalami penurunan kedisplinan saat belajar dirumah. Hal ini dikarenakan banyak siswa menganggap bahwa sekolah adalah kegiatan yang sangat menyenangkan, mereka bisa berinteraksi satu sama lain. Sekolah dapat meningkatkan keterampilan sosial dan kesadaran kelas sosial siswa. Sekolah merupakan media interaksi antar siswa dan guru untuk meningkatkan kemampuan berpikir, ketrampilan dan rasa kasih sayang diantara sesama. Akan tetapi untuk saat ini kegiatan yang disebut sebagai sekolah berhenti dengan tiba-tiba akibat pandemi Covid-19(Syah, 2020). 
Hal ini mengakibatkan kepedulian dan peran orang tua sangat diibutuhkan untuk mengawasi siswa belajar dirumah secara daring. Orangtua memiliki peran penting dalam menjaga dan membina perkembangan anak apalagi di sistem belajar online seperti sekarang ini. Orangtua harus memiliki banyak waktu bersama anak-anak sehingga anak dapat terus berkembang melalui pengasuhan yang diberikan orangtua. Akan tetapi, kegiatan belajar dari rumah banyak mendapat penolakan dari orangtua, karena salah satu alasan terbesar dari orangtua adalah mayoritas orangtua tidak paham dengan teknologi yang digunakan dalam proses belajar daring(Kusuma, 2020) .

Pembelajaran daring banyak dilakukan dengan berbagai platform / aplikasi yang diterapkan di Indonesia, salah satunya ialah aplikasi google classroom(Yu-Fong Chang, Wang, Lin, Cheng, \& Chiang, 2021). Pembelajaran online yang diterapkan dengan menggunakan media goggle calssroom memungkinkan pengajar dan peserta didik dapat melangsungkan pembelajaran tanpa melalui tatap muka di kelas dengan pemberian materi pembelajaran (berupa slide power point, e-book, video pembelajaran, tugas (mandiri atau kelompok), sekaligus penilaian(PalazónHerrera \& Soria-Vílchez, 2021). Selain menggunakan aplikasi google classroom, pembelajaran daring juga menggunakan media berbasis meet atau rapat secara virtual. Media daring meeting menggunakan perangkat lunak berbasis mobile atau berbasis website (Subarkah, Abdallah, Oktaviani, \& Hidayah, 2021).

Berdasarkan uraian permasalahan pada mitra, tim pengusul bermaksud memberikan pelatihan media pembelajaran berbasis daring bagi orang tua guna untuk mengedukasi para orang tua agar memahami dan bisa memantau kegiatan belajar para siswa dirumah bisa belajar secara optimal.

\section{METODE}

Sumber Metode pelaksanaan dalam
kegiatan pengabdian masyaraka ini
menggunakan Participatory Action Research (PAR). PAR merupakan salah satu pendekatan yang mengombinasikan antara penelitian dengan tindakan yang berkelanjutan( $\mathrm{M}$. Kindon, S., Pain, R., \& Kesby, 2007). Berpijak pada problematika yang dihadapi oleh subjek dampingan, menjadikan PAR sebagai pilihan metode yang tepat sebagai upaya untuk memberikan alternatif solusi pemecahan masalah yang ada.

Secara teknis, kegiatan pengabdian terdiri dari empat tahapan berikut ini :
1. Persiapan

Pada tahapan awal dilakukan observasi guna mengidentifikasi permasalahan dan peluang mitra dampingan. Sehingga didapatkan alternatif solusi dari permasalahan mitra.

2. Pelaksanaan

Pelaksanaan Pelakasanaan kegiatan meliputi kegiatan pelatihan terhadap penggunaan media pembelajaran daring kepada para orangtua, sehingga mereka dapat melakukan pendampingan terhadap anak saat pelaksanaan pembelajaran daring. Serta kegiatan monitoring atau pendampingan peserta, dimana kegiatan dilakukan dengan membangun konsultasi secara online atas kegiatan pelatihan yang telah dilakukan sebelumnya. Kegiatan monitoring diisi dengan menanyakan penggunaan media pembelajaran daring yang telah mereka jalankan serta memberikan solusi atas permasalahan tersebut

3. Evaluasi

Tujuan kegiatan evaluasi untuk menentukan tingkat keberhasilan pelaksanaan program. Evaluasi dilakukan menggunakan pretest dan post tes serta lembar evaluasi oleh subjek dampingan, yaitu pada peserta kegiatan pelatihan

\section{HASIL DAN PEMBAHASAN}

Pelaksanaan kegiatan dilangsungkan secara daring dengan media zoom hari Jum'at tanggal 30 Juli 2021. Satu bulan sebelumnya tim melakukan publikasi kegiatan pelatihan media pembelajaran daring dengan menyebarkan poster dan melakukan broadcast dari media sosial hal ini ditujukan agar dapat menjaring minat masyarakat luas untuk dapat mengikuti kegiatan pelatihan ini. Tim juga menyediakan doorprize kepada 8 orang peserta yang beruntung untuk memotivasi kepada peserta yang ikut berpartisipasi dalam kegiatan pelatihan ini

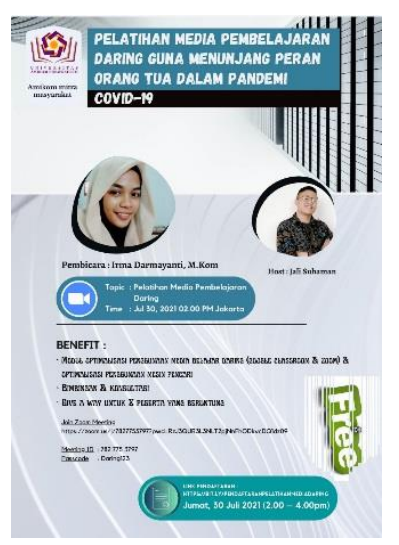

Gambar 1. Poster Kegiatan 
Kegiatan pelatihan ini dilaksanakan dari peserta yang telah melakukan pendaftaran baik secara online maupun offline dimana link pendaftaran sudah tercantum pada poster yang sudah disebarkan oleh tim. Kemudian peserta yang mendaftar oleh tim dimasukan kedalam grup whatsapp untuk memudahkan tim dan peserta berkoordinasi. Grup whatsapp sendiri juga digunakan sebagai media konsultasi secara online kepada peserta setelah mengikuti keiatan pelatihan ini.

Kegiatan diikuti oleh 59 peserta yang terdiri dari kalangan orangtua, pelajar dan mahasiswa. Diawal kegiatan host memberikan pre-test kepada peserta yang bergabung guna menggali informasi akan seberapa mengenal dan mengerti peserta terhadap teknologi yang diulas pada kegiatan pelatihan ini, dan sebanyak $56 \%$ peserta sudah mengetahui namun masih mempunyai kendala dalam pemakaiannya dan sisanya masih baru mengenal dengan teknologi yang digunakan pada proses pembelajaran secara daring.

Kegiatan berlangsung dengan pemateri memaparkan materi power point yang terbagi menjadi tiga sesi,dimana sesi pertama untuk memaparkan materi dan melakukan praktek secara langsung pada aplikasi Google Classroom, sesi kedua untuk memaparkan materi dan melakukan praktek secara langsung pada aplikasi Zoom Cloud Meeting dan sesi ketiga memaparkan materi dan melakukan praktek secara langsung melakukan penulusuran dengan Google.

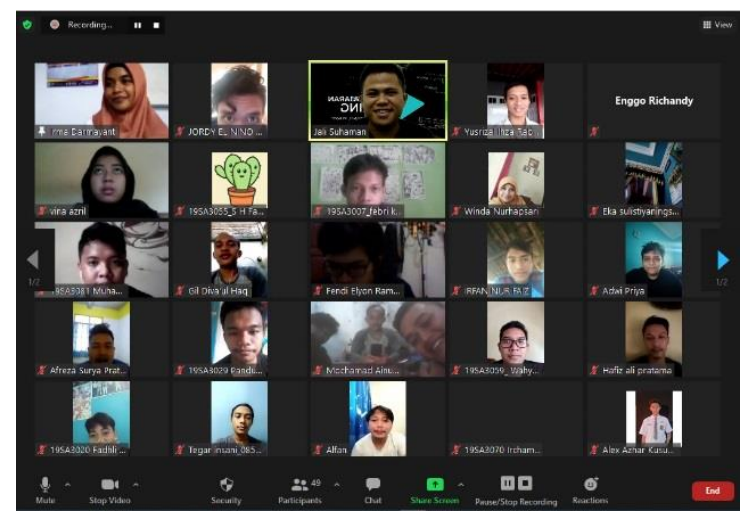

Gambar 2. Pelaksanaan Kegiatan

Pada masing-masing sesi dijeda untuk kegiatan Tanya jawab, dimana peserta dapat mengajukan pertanyaan pada materi yang telah dipaparkan atau menjawab pertanyaan yang diajukan dari pemateri maupun host. Pada sesi Tanya jawab, peserta sangat antusias mengikuti karena adanya doorprize yang dibagikan pada peserta yang berhasil menjawab pertanyaan ataupun pada peserta yang mengajukan pertanyaan terbaik. Diakhir sesi pun ada 2 doorprize yang dibagikan secara acak, serta tim membagi link kuisioner posttest yang diisi oleh 59 peserta yang hadir dimana postest ini bertujuan untuk menggali pemahaman akan media pembelajaran daring peserta setelah kegiatan pelatihan selesai, serta pembagian modul pada seluruh peserta.

Kegiatan berlangsung dengan lancar, dan peserta dapat menerima pemaparan materi dengan baik terlihat dari rata-rata jawaban postest sebanyak $74,58 \%$ peserta sudah dapat memahami penggunaan media pembelajaran daring. Dengan demikian kegiatan pengabdian ini cukup efektif dilakukan terlihat sebanyak $56 \%$ peserta diawal mengalami kesulitan pada penggunaan media pembelajaran daring setelah mengikuti pelatihan terdapat peningkatan pengetahuan pada masingmasing peserta.

\section{SIMPULAN DAN SARAN}

Di masa pandemi pemanfaatan teknologi sebagai salah satu upaya agar siklus belajar tetap terlaksana dengan baik. Oleh karena itu, setiap pelajar harus bisa menggunakan dengan baik media pembelajaran daring yang digunakan oleh sekolah masing-masing untuk memudahkan guru dalam menjalankan tugasnya dan proses pendidikan tetap berjalan.

Pemanfaatan teknologi juga harus didukung dengan peran orangtua dalam mengawasi proses pembelajaran dari rumah. Untuk itu orangtuapun sedapat mungkin harus dapat mengerti penggunaan berbagai aplikasi media belajar sehingga orangtua dapat mengoptimalkan proses belajar anak-anak mereka meski sebatas belajar dari rumah. Sehingga, kualitas pendidikan daringpun dapat optimal dengan adanya pengetahuan yang baik baik orangtua maupun siswa terhadap pemanfaatan teknologi pembelajaran daring itu sendiri. Keterbatasan pelatihan ini tidak dapat dilakukan secara offline karena adanya kebijakan PPKM yang masih terus dperpanjang.

\section{UCAPAN TERIMAKASIH}

Penulis mengucapkan terima kasih kepada Lembaga Penelitian dan Pengabdian kepada Masyaraka (LPPM) Universitas Amikom Purwokerto yang sudah memberikan bantuan melalui Program Amikom Mitra Masyarakat tahun 2021 dan Penulis ucapkan terima kasih kepada Jurnal Selaparang yang sudah memberikan kesempatan sehingga jurnal pengabdian ini terbit.

\section{DAFTAR RUJUKAN}

Ananda, Rizki., Fadhilaturrahmi., I. H. (2021). Dampak Pandemi Covid-19 terhadap Pembelajaran Tematik di Sekolah Dasar. 
Jurnal Basicedu, 5(3), 1689-1694.

Kusuma, W. (2020). Survey Mahasiswa Kepada Orang Tua Siswa Terhadap Pembelajaran Daring. Retrieved June 30, 2021, from https://jurnalpost.com/surveymahasiswa-kepada-orang-tua-siswaterhadap-pembelajaran-daring/14574/

M. Kindon, S., Pain, R., \& Kesby. (2007). Participatory action research approaches and methods: Connecting people, participation and place. Routledge.

Palazón-Herrera, J., \& Soria-Vílchez, A. (2021). Students' perception and academic performance in a flipped classroom model within Early Childhood Education Degree. Heliyon, 7(4). https://doi.org/10.1016/j.heliyon.2021.e06 702

Subarkah, P., Abdallah, M. M., Oktaviani, S., \& Hidayah, N. (2021). Pelatihan Penggunaan Virtual Meeting Untuk Mendukung Kegiatan Belajar Mengajar Bagi Guru, 5(4), 1214-1223.

Syah, R. H. (2020). Dampak Covid-19 pada Pendidikan di Indonesia: Sekolah, Keterampilan, dan Proses Pembelajaran. SALAM: Jurnal Sosial Dan Budaya Syar-I, $7(5)$.

https://doi.org/10.15408/sjsbs.v7i5.15314

Yu-Fong Chang, J., Wang, L. H., Lin, T. C., Cheng, F. C., \& Chiang, C. P. (2021). Comparison of learning effectiveness between physical classroom and online learning for dental education during the COVID-19 pandemic. Journal of Dental Sciences, 16(4), 1281-1289. https://doi.org/10.1016/j.jds.2021.07.016 